\title{
PRODUÇÃO DE SENTIDOS A PARTIR DA LEITURA DE ESQUEMAS DIDÁTICOS REPRESENTATIVOS DA RESPIRAÇÃO HUMANA
}

\author{
Jacqueline Ribeiro de Souza Mendes ${ }^{1}$ \\ Maria Helena da Silva Carneiro²
}

\section{RESUMO}

Esquemas são representações visuais presentes nos livros didáticos de Ciências e Biologia, frequentemente utilizados no ensino e aprendizagem dessas disciplinas. Pesquisas apontam, entretanto, dificuldades na interpretação dessas representações pelos alunos. Investigamos a produção de sentidos a partir da leitura de esquemas representativos de processos envolvidos no fenômeno da respiração, conteúdo trabalhado ao longo da educação básica. Participaram três alunas de Licenciatura em Ciências Biológicas que realizaram atividades de leitura e produção de esquemas durante entrevistas individuais. Definimos níveis de leitura para a análise dos dados a partir dos conceitos de iconografia e iconologia propostos por Panofsky (1976), e dos conceitos de sintaxe, semântica e pragmática utilizados por Calado (1994) em estudo sobre imagens em contextos educativos. Identificamos diferentes níveis de interpretação para um mesmo esquema, o que pode estar relacionado à familiaridade das participantes com elementos icônicos e simbólicos utilizados na produção dessas representações visuais, bem como a conhecimentos prévios acerca da respiração, em alguns casos em desacordo com o conhecimento científico vigente ou em um nível aquém do esperado no grau de escolarização das alunas. Enfatizamos a necessidade de discutir, em cursos de formação de professores, questões relacionadas à produção, leitura e utilização de esquemas.

Palavras-chave: Leitura. Imagens. Esquema. Respiração.

\section{THE PRODUCTION OF MEANING BASED ON READING OF SCHEMATIC REPRESENTATIONS OF RESPIRATION PHENOMENON}

\section{ABSTRACT}

Schemes are visual representations present in Science and Biology textbooks, frequently used as tools for teaching and learning these disciplines. However, research indicates that students face challenges in interpreting these visual representations. This paper examines the production of meanings based on the reading of schematic representations of processes involved in the respiration phenomenon. Three Biological Sciences undergraduate students participated in the study by carrying out reading and producing schemes during individual interviews. We developed a framework for data analysis based on iconography and iconology concepts proposed by Panofsky (1976), as well as syntax, semantics and pragmatics concepts used by Calado (1994) in a study of images in educational contexts. We identified that students present different levels of reading for the same scheme, which may be due to the participants' familiarity with iconic and symbolic elements used in the production of these visual representations, as well as students' previous knowledge on respiration that, in some cases, were at odds with the existing scientific knowledge or were at a level below the participants' expected level of schooling. As a result, we emphasise that further discussions of issues related to the production, reading and use of schemes should be considered in teacher training courses. Keywords: Scheme. Visual representations. Reading. Respiration.

Recebido em: 6/4/2020

Aceito em: $7 / 5 / 2020$

\footnotetext{
Doutoranda do Programa de Pós-Graduação em Educação Científica do Instituto de Química - Universidade de Brasília. Graduação em Licenciatura em Ciências Biológicas (1983) e Mestrado em Educação na área de Magistério, Formação e Trabalho Pedagógico (2006) pela Universidade de Brasília. Especialização em Metodologia da Educação a Distância pela Universidade do Sul de Santa Catarina. Atuação como docente de Ciências e Biologia nas redes pública e privada de ensino do Distrito Federal e Colégio Militar de Brasília, em Instituições de Ensino Superior nos cursos de Pedagogia e Ciência da Educação e na coordenação de cursos de Pós-Graduação Lato Sensu. Coordenou a Educação de Jovens e Adultos a Distância da Secretaria de Educação do Distrito Federal. Professora formadora na Licenciatura a Distância na Universidade Aberta do Brasil (UAB-UnB). http://lattes.cnpq.br/7496471232303405. https://orcid.org/0000-0002-7121-7966. rsmjacqueline@gmail.com

2 Mestrado em Ecologia Humana (Université Paris Descartes, 1978). Mestrado em Didática das Disciplinas: Biologia (1981) e Doutorado em Didática das disciplinas: Biologia (1992) pela Universidade de Paris VII (reconhecido para fins de concurso: UFSC-1993). Professora associada da III Faculdade de Educação da Universidade de Brasília. Tem experiência na área de Educação, com ênfase em Educação Científica, atuando principalmente nos seguintes temas: aprendizagem de conceitos científicos, ensino de ciências, ensino de biologia, imagens e ensino de ciências, livro didático e aprendizagem e divulgação do conhecimento científico. http://lattes.cnpq.br/5180655115687228. https://orcid.org/0000-0001-7716-6875. airamcarneiro@gmail.com
} 
A investigação relatada neste artigo foi realizada com professores em formação, licenciandos em Ciências Biológicas. Buscamos identificar, especificamente, diferentes níveis de leitura de imagens do tipo esquema, representativos de estruturas e processos envolvidos no fenômeno da respiração humana, com o objetivo de compreender como o leitor produz sentidos a partir da leitura desse tipo de imagem.

O discurso científico caracteriza-se pela presença de diferentes modos de representação, como o verbal, o visual e o gestual. Também a "ciência escolar", veiculada nos livros didáticos, lança mão de textos verbais acompanhados de uma variedade de representações visuais, entre elas fotografias, esquemas, desenhos, gráficos e infográficos.

Com base nos resultados de um estudo sobre a utilização de imagens em contextos educativos, realizado com professores do Ensino Médio em Portugal, Calado (1994) afirma que os educadores reconhecem as potencialidades pedagógicas das representações visuais. Elas desempenham uma função de complementação do texto, auxiliando os estudantes na compreensão de experiências práticas e de conceitos, e também nas abstrações (BARLEX; CARRÉ, 1985; BUCKLEY, 2000), constituem outra forma de apresentar a informação com o potencial de ampliar a aprendizagem conceitual (CHENG,1999), e motivam o leitor para o conteúdo apresentado no texto, ou, conforme salienta Martins (1997),

[...] há imagens que, num certo sentido, são o próprio conteúdo. Embora a cultura científica ainda privilegie o conhecimento expresso através da linguagem, há conceitos cuja visualização é essencial para sua conceitualização e compreensão. Não conhecer a estrutura da dupla hélice é não conhecer o ADN; quem não sabe a forma de campos magnéticos, não sabe magnetismo (p. 298).

Roth, Pozzer-Ardenghi e Han (2005), entretanto, alertam para o fato de que a proliferação de representações visuais nos livros didáticos não garante eficiência na comunicação de conceitos científicos. Apontamos, com base em nossa experiência docente, ${ }^{3}$ que, por vezes, essas representações podem se constituir em fonte de equívocos, dependendo da forma como são construídas e utilizadas tanto pelos professores quanto pelos alunos.

Um tipo de representação visual bastante comum no ensino e aprendizagem das disciplinas científicas, e muito frequente nos livros didáticos, são os esquemas, embora pesquisas tenham evidenciado que os estudantes apresentam dificuldades na sua interpretação (BOWEN; ROTH, 2002; CHITTLEBOROUGH; TREAGUST, 2008; KOTZEBUE; GERSTL; NERDEL, 2015), e o seu uso no aprendizado de ciências pode ser desafiador para os estudantes (LIU; WON; TREAGUST, 2014).

A respiração humana é um conteúdo trabalhado ao longo da Educação Básica, com diferentes níveis de complexidade, e os esquemas são muito utilizados e frequentes nos materiais didáticos. É possível atribuir diversas funções às representações esquemáticas no ensino e aprendizagem da respiração humana: complementar o texto verbal; representar estruturas anatômicas, bem como relações entre estruturas e funções; representar fenômenos que ocorrem em âmbito microscópico, entre outras.

Experiência de mais de 30 anos em docência de Ciências e Biologia na Educação Básica e no Ensino Superior. 
Apesar da familiaridade com os esquemas e com o estudo da respiração, considerando sua recorrência ao longo da Educação Básica, muitos alunos finalizam essa etapa da escolarização com dificuldade na leitura de esquemas e sem a compreensão articulada do fenômeno respiratório, que envolve conteúdos de diferentes áreas do conhecimento, como a Química, a Física e a Biologia.

Estudos nacionais e internacionais realizados com alunos da Educação Básica (LUÍS, 2004; SÁ; JÓFILI; CARNEIRO-LEÃO, 2005; ACEDO; FIEDLER-FERRARA JÚNIOR, 2008), da Educação Superior (SÁ; SOUZA; JÓFILI, 2014; SÁ et al., 2015; BAJD; PRAPROTNIK; MATIAŠEK, 2010) ou ambos os níveis de educação (ASCI; ÖZKAN; TEKKAYA, 2001; SÁ; JÓFILI; CARNEIRO-LEÃO, 2011), evidenciaram, a despeito da diferença na escolaridade dos sujeitos investigados, semelhanças quanto à dificuldade dos alunos em articular conceitos de diferentes áreas do conhecimento, obstaculizando a compreensão do processo respiratório em sua totalidade.

Foi apontado, ainda, que os discentes mantêm concepções em desacordo com o conhecimento científico vigente, mesmo que tenham passado por um longo processo de educação formal. Destacam-se, entre elas, as concepções da respiração como um processo de limpeza do sangue, de oposição à fotossíntese, de conversão da glicose em amido, sem citar todas. Partindo de estudos realizados por outros pesquisadores, Asci, Özkan e Tekkaya (2001) e Kwen (2005) sumarizaram possíveis origens dessas concepções: uso de linguagem cotidiana em contextos científicos; observações e experiências do indivíduo em sua vida cotidiana; raciocínio a partir da experiência sensorial; conhecimento inadequado do conteúdo por parte do professor; estratégias de ensino; apresentação de conceitos de forma compartimentada; detalhamento excessivo, resultando uma aprendizagem por memorização; sequência de apresentação, falta de integração, incorreção das informações e ausência de figuras e exemplos nos livros didáticos, bem como os esquemas presentes nesses livros.

Tendo em conta o que foi pontuado acerca da dificuldade de compreensão do fenômeno respiratório por parte de alunos em diferentes níveis de escolaridade, a existência de concepções persistentes que influenciam a construção de novos conhecimentos e as dificuldades na interpretação de representações visuais esquemáticas, presentes nos livros didáticos, empreendemos um estudo no qual buscamos compreender a produção de sentidos por parte de um grupo de licenciandos em Ciências Biológicas a partir da leitura de esquemas que representam estruturas e processos envolvidos no fenômeno da respiração humana.

\section{CONSIDERAÇÕES CONCEITUAIS}

O termo esquema tem sido utilizado com uma variedade de significações, tais como sinopse, plano, resumo, esboço, entre outras. Dessa forma, é relevante explicitar que, no âmbito deste trabalho, consideramos esquema uma representação visual do tipo imagem material fixa, bidimensional, elaborada com o propósito didático de representar estruturas, relações, processos e fenômenos, objetos de estudo das disciplinas científicas. 
É também pertinente tecer considerações referentes à leitura e, para tanto, citamos a reflexão de Koch e Elias (2008) sobre leitura, texto e sentido com base em três focos distintos: no autor, no texto e na interação autor-texto-leitor.

No primeiro caso, cabe ao sujeito leitor, sem que sejam consideradas suas experiências e conhecimentos prévios, captar as intenções e as ideias do autor do texto. Ao deslocar o foco para o texto, no segundo caso, admite-se que ao leitor compete reconhecer o sentido das palavras e estruturas do texto. Essas duas concepções de leitura compartilham a ideia de que cabe ao leitor apenas a tarefa de reconhecer e de reproduzir.

No terceiro caso, quando o foco recai sobre a interação entre o autor, o texto e o leitor, as autoras consideram a leitura uma atividade dialógica, em que o sentido de um texto se constrói a partir da interação entre ele e os sujeitos autor e leitor, com base na forma de organização dos elementos linguísticos presentes na superfície textual, mobilizando um vasto conjunto de saberes na realização do evento comunicativo.

Ao afirmarem que "ler é produzir sentido", Martins, Picosque e Guerra (1998, p. 4) alinham-se à visão de leitura como processo de interação, pois se depreende da afirmação que o sentido do texto não é inerente a ele, mas produzido por um sujeito que o lê e que com ele interage.

De forma semelhante, Walty, Fonseca e Cury (2000, p. 39) manifestam que "o leitor é um produtor de sentidos e traz para o interior do 'mundo de papel' toda uma gama de elementos extratextuais", conhecimentos prévios, expectativas e visão de mundo que irão determinar a qualidade e a intensidade da interação.

Todas as afirmações anteriores referem-se à leitura de textos escritos. Defendemos, entretanto, a ideia de que a leitura é um ato aplicável também às imagens, posição igualmente adotada por Manini (2011) ao considerar provável que a primeira leitura tenha sido de imagens registradas em paredes de cavernas.

Calado (1994) também aceita a leitura da imagem e, ainda, amplia a aplicação à linguagem visual de conceitos referentes à linguagem verbal, com o argumento de que

na verdade, a partir do momento em que admitimos que as imagens materiais são sistemas de representação, podemos utilizar, a propósito da linguagem visual e com toda a pertinência, os conceitos de leitura, alfabetização e aprendizagem (p. 21).

Essa visão traz relevantes contribuições para o ensino e aprendizagem das disciplinas científicas. Nela, está implícita a ideia de que a leitura de imagens não é imediata, mas carece de um aprendizado. Isso alerta para que sejam revistas práticas pedagógicas centradas na utilização de imagens e que tenham como pressuposto a transparência desses recursos.

Ao discorrer sobre leitura de imagens materiais em contextos educacionais, Calado (1994) faz referência aos conceitos de sintaxe, semântica e pragmática, operacionalizados por Goldsmith em 1984. No nível sintático, a leitura é uma resposta aos sinais gráficos que definem a imagem como tal e diz respeito ao reconhecimento da imagem em termos de seu contorno, dos seus limites. O nível semântico corresponde à identifi- 
cação literal da imagem e refere-se às significações que o seu autor teve intenção de lhe conferir. No nível pragmático, o leitor realiza a interpretação, acrescentando sentidos às intenções do autor a partir da sua visão de mundo e de suas experiências.

Em relação à leitura de obras de arte, Panofsky (1976) identifica três níveis. No primeiro, que se constitui em uma descrição pré-iconográfica, são identificadas as chamadas formas puras, tais como configurações de linhas e cores, representações de objetos naturais, seres humanos, plantas, casas, ferramentas, animais, etc. No nível iconográfico, o significado é apreendido por intermédio da identificação de determinadas ordens ou configurações, por meio das quais se relacionam as tais formas puras. No terceiro nível - o iconológico - o significado ou conteúdo da obra é desvelado quando são identificados princípios subjacentes que possibilitam identificar em uma obra, por exemplo, crenças religiosas. São valores simbólicos atribuídos ao resultado da análise iconográfica.

Dito de forma sucinta, porém sem reduzir a complexidade da proposta do autor, a distinção possível entre os níveis iconográfico e iconológico reside na igual distinção entre análise e interpretação. A leitura da imagem no nível iconográfico compreende uma análise no sentido restrito de decomposição de um todo em suas partes constituintes. A leitura realizada no nível iconológico é uma interpretação, um ato de julgamento e avaliação.

Entendemos, dessa forma, que a leitura de uma imagem é um processo de construção de sentidos que se dá a partir da mobilização dos conhecimentos e experiências prévias do leitor, que os utiliza para interagir com os elementos constitutivos da imagem identificados em diferentes níveis.

Assim, para fins desta investigação, reunimos os atributos dos níveis pré-iconográfico, iconográfico, sintático e semântico em um nível de leitura ao qual chamaremos de leitura de superfície ou leitura de identificação, aqui entendido como o nível em que é realizada a análise da imagem no sentido explicado anteriormente. Igualmente, reuniremos os níveis iconológico e pragmático em um nível ao qual denominaremos de leitura em profundidade ou leitura interpretativa, no qual o leitor mobiliza conhecimentos e experiências prévias para a produção do sentido do texto a partir da interação com ele.

\section{PERCURSO METODOLÓGICO}

A investigação foi realizada com três estudantes de Licenciatura em Ciências Biológicas, professoras em formação, cursando diferentes semestres, identificadas como A7, B9 e C7. Os números 7 e 9 referem-se ao semestre cursado pelas participantes, sétimo e nono respectivamente.

A coleta de dados foi feita por meio de entrevistas individuais, com duração média de 60 minutos cada uma, divididas em dois momentos. Primeiramente, realizamos o levantamento das concepções das estudantes acerca do fenômeno da respiração humana. No segundo momento da entrevista, focamos na elaboração e leitura de esquemas. 


\section{Momento 1 - Levantamento de concepções}

Para identificar as concepções das entrevistadas acerca da respiração, solicitamos que respondessem, por escrito, a um questionário composto por cinco questões, impressas em folhas separadas. As questões foram entregues sequencialmente, à medida que a entrevistada fosse devolvendo a folha com a resposta antecedente. Buscamos, com essa dinâmica, evitar que o enunciado de uma questão pudesse servir de pista ou influenciar a resposta às questões subsequentes. A interpretação do enunciado fazia parte da questão, de maneira que nenhuma explicação adicional foi dada durante a realização dessa primeira atividade, que durou em média 15 minutos.

Elaboramos as questões com base em levantamentos das concepções sobre respiração humana de alunos em diferentes níveis de escolaridade, realizados por diversos pesquisadores no Brasil e em outros países, como Banet e Núñez (1996), Asci, Özkan e Tekkaya (2001), Luís (2004), Sá, Jófili e Carneiro-Leão (2005, 2009, 2011), Acedo e Fiedler-Ferrara Júnior (2008), Sá, Souza e Jófili (2014), Sá et al. (2015) e Bajd, Praprotnik e Matyašek (2010).

\section{Momento 2 - Elaboração e leitura de esquemas}

O segundo momento da entrevista consistiu na realização de atividades de elaboração e leitura de esquemas, durante as quais as participantes foram solicitadas a verbalizar o pensamento. O registro em áudio das verbalizações foi, posteriormente, transcrito para análise, conforme autorização prévia concedida pelas alunas.

\section{Atividade 1 - Elaboração de esquema}

Esta atividade teve como objetivo evidenciar o conhecimento acerca da respiração e o domínio na utilização de elementos icônicos e simbólicos comumente empregados na elaboração de esquemas representativos desse fenômeno.

Cada entrevistada recebeu o contorno de um corpo humano impresso em folha de papel branco, e um kit contendo folhas de papel, borracha e lápis de cores diversas. Solicitamos que traçassem, esquematizassem ou descrevessem o trajeto dos gases respiratórios $\mathrm{O}_{2}$ e $\mathrm{CO}_{2}$ do meio externo ao interior do corpo e de volta ao meio externo. $\mathrm{O}$ uso dos materiais disponibilizados foi de livre-escolha.

\section{Atividade 2-Leitura de esquemas}

Esta segunda atividade foi dividida em duas partes: leitura e legendamento de esquemas. Foram usados nessa atividade três esquemas da respiração humana, copiados de um livro didático de Biologia (AMABIS; MARTHO, 2009) tradicionalmente adotado em escolas de educação básica no Distrito Federal.

Entregamos os esquemas ampliados em relação à dimensão original, mantivemos a sua apresentação em cores e retiramos as legendas, de forma que nenhuma informação verbal fosse acrescentada ou servisse de pista para a leitura. Nosso interesse era evidenciar a leitura e a interpretação dos elementos constituintes dos esquemas, que foram apresentados separadamente, de forma que cada um deveria ser lido e legendado por escrito, antes que outro esquema fosse entregue com o mesmo propósito. 


\section{ANÁLISE E DISCUSSÃO DOS DADOS}

Nesta seção apresentaremos dados obtidos nos dois momentos da entrevista, acompanhados das respectivas análises.

\section{Momento 1 - Levantamento de concepções}

As entrevistadas responderam a um questionário, apresentado a seguir juntamente com as respostas de A7, B9 e C7 transcritas literalmente, ${ }^{4}$ composto por cinco questões abertas, envolvendo conhecimentos genéricos relacionados à respiração. A partir da análise das respostas, foi possível levantar algumas hipóteses em relação às concepções das alunas sobre o processo respiratório, que corroboram estudos realizados por outros pesquisadores.

\section{Questão 1: Qual a finalidade da respiração?}

A7 - Realizar trocas gasosas nos pulmões para trazer oxigênio e liberar gás carbônico.

B9 - A respiração tem como finalidade levar oxigênio para dentro do nosso organismo, para que diferentes atividades aconteçam.

C7 - Basicamente a respiração é de tamanha importância, visto que é a partir deste mecanismo que os seres vivos obtêm o oxigênio para o funcionamento do seu organismo. Sem este mecanismo, o ser vivo morre.

Deliberadamente, não especificamos se a pergunta referia-se à respiração pulmonar ou celular para evitar induzir as respostas. Observamos que nenhuma das alunas fez referência à respiração como um processo de oxidação de moléculas orgânicas para a obtenção de energia, ou seja, à respiração celular. Dessa forma, ficou evidente a compreensão da respiração apenas como um processo de trocas gasosas entre o organismo e o meio, corroborando resultados de pesquisas realizadas por Jófili e Carneiro-Leão (2005, 2011), Acedo e Fiedler-Ferrara Júnior (2008), Asci, Özkan e Tekkaya (2001) e Bajd, Praprotnik e Matyašek (2010) com alunos de educação básica e superior.

Embora as alunas já estejam no final da Graduação em Licenciatura em Ciências Biológicas, o conhecimento sobre um fenômeno importante, como a respiração, permanece ainda em nível superficial, sem que sejam estabelecidas as relações entre os processos que ocorrem em nível pulmonar e os que ocorrem em nível celular, que não foram citados por nenhuma das entrevistadas. A resposta de A7 à segunda questão ilustra essa afirmação:

[...] o sistema circulatório leva o sangue para o corpo todo e esse sangue precisa conter oxigênio $\left(\mathrm{O}_{2}\right)$; este é levado para as células para participar de diversos processos [...].

${ }_{4}$ Todas as transcrições neste artigo são literais. Com esta observação, estamos evitando a repetição da expressão [sic]. 
Não foi explicitado, entretanto, o porquê de o sangue precisar conter oxigênio nem quais eram os diversos processos dos quais o oxigênio participaria.

A aluna B9 avançou um pouco, mas, ainda assim, de forma bastante genérica, reconheceu que a respiração está relacionada a outros processos no organismo, ao responder que "a respiração tem como finalidade levar oxigênio para dentro do nosso organismo para que diferentes atividades aconteçam". Assim como A7, todavia, não citou a que atividades se referia e, dessa forma, não ficou claro se a aluna compreendia a relação entre as trocas gasosas e a respiração celular. Como foi apontado por Sá et al (2015), a aprendizagem de conceitos permanece no campo macroscópico sem que seja estabelecida integração com o universo microscópico.

Questão 2: Existe relação entre os sistemas respiratório e circulatório? Caso positivo, descreva essa relação.

A7 - Sim, o sistema circulatório leva o sangue para o corpo todo e esse sangue precisa conter oxigênio $\left(\mathrm{O}_{2}\right)$; este é levado para as células para participar de diversos processos e é nos pulmões onde o sangue adquire o oxigênio necessário. Ambos trabalham intimamente ligados.

B9 - Sim, há relação entre os dois sistemas. A respiração se inicia com a entrada de ar pelas cavidades nasais, indo até os bronquíolos. Nos bronquíolos, o ar entra em contato com diversos capilares sanguíneos, onde, por difusão, o $\mathrm{O}_{2}$ respirado entra e o $\mathrm{CO}_{2}$ produzido pelo corpo sai. $\mathrm{O} \mathrm{O}_{2}$ que entra vai caminhando pelo corpo até chegar nas células, através dos vasos.

C7 - Sim, o oxigênio adquirido pela respiração é transportado pelas hemácias. Então ambos os sistemas estão interligados.

A segunda questão confirma os resultados da primeira, ainda que a pergunta tenha se referido à relação entre os sistemas circulatório e respiratório. As respostas continuaram em um nível superficial, sem um aprofundamento que demonstrasse conhecimento além da relação com base no transporte dos gases $\mathrm{O}_{2}$ e $\mathrm{CO}_{2}$.

A relação entre a ventilação pulmonar, o ritmo cardíaco e a pressão parcial desses gases no sangue, não foi citada. Além disso, B9 apresentou um vocabulário que transitou entre o acadêmico e o leigo, de certa forma infantilizado, ao referir-se ao transporte do gás oxigênio "que entra vai caminhando pelo corpo até chegar nas células".

A confusão entre inspiração e respiração também ficou clara no uso de uma expressão pela outra, quando B9 expressa que "nos bronquíolos, o ar entra em contato com diversos capilares sanguíneos, onde, por difusão, o $\mathrm{O}_{2}$ respirado entra e o $\mathrm{CO}_{2}$ produzido pelo corpo sai". Esse dado corrobora as observações de Asci, Özkan e Tekkaya (2001) em estudo realizado com alunos de educação básica e superior. Esses pesquisadores identificaram imprecisão de linguagem quando os alunos se referiam à respiração (respiration) como sinônimo de inspiração e expiração (breathing).

Questão 3: Durante a inspiração, nossos pulmões se expandem, ao passo que, ao expirarmos, nossos pulmões se contraem, tornando-se menores do que o tamanho normal. Comente a afirmação.

A7 - Ao meu ver está correto, porém eu citaria a atividade que o diafragma realiza durante o processo. 
B9 - Ao inspirar, a caixa torácica se expande e o diafragma aumenta, assim a pressão nos pulmões muda e o ar consegue entrar. Já na expiração, há o relaxamento do diafragma e músculos da caixa torácica, fazendo com que o ar saia.

C7 - Durante a inspiração, os pulmões se expandem para encher o pulmão de ar e se contraem liberando o gás carbônico. Então está certo.

Com essa questão, nosso objetivo foi identificar o conhecimento sobre a mecânica da ventilação pulmonar. Em relação a esse aspecto, é possível afirmar que as alunas identificaram corretamente a existência dos estados de contração e expansão dos pulmões. A exemplo, porém, das situações descritas nas duas questões anteriores, também em um nível básico. Nenhuma das alunas impôs objeção à informação, incorreta, de que durante a expiração o pulmão se contrai tornando-se menor do que o tamanho normal, uma situação que caracterizaria a falência ou o colapso do pulmão.

As questões quatro e cinco buscaram levantar dados sobre o conhecimento acerca da composição do ar e a relação com a concepção de que o ar expirado é sujo por conter mais gás carbônico, e com a concepção de que a respiração serve para a troca do ar sujo do pulmão por ar limpo.

Questão 4: Nos livros didáticos de Ciências e Biologia, é comum encontrarmos a afirmação de que "o ar inspirado é rico em oxigênio e pobre em gás carbônico". Comente a afirmação.

A7 - Para fins didáticos, a nível de Ciências, Ensino Fundamental, creio que é válido citar a variação das concentrações de gás carbônico, devido à poluição do ambiente. Além de citar da enorme porcentagem de nitrogênio presente no ar.

$\mathrm{B9}$ - Na verdade, o ar é rico nos dois gases, $\mathrm{O}_{2}$ e $\mathrm{CO}_{2}$, mas as pressões atmosféricas destes gases são diferentes e suas pressões nos pulmões também. E são esses valores que diferenciam uma maior entrada de ar na inspiração.

C7 - Aprendi desta forma e nunca me atentei a esta afirmação, portanto creio que esteja correta.

Questão 5: Comente a afirmação: $O$ ar inspirado contém mais oxigênio do que gás carbônico, ao passo que o ar expirado contém mais gás carbônico do que oxigênio.

A7 - Acredito que seja verídico, pois nos alvéolos o oxigênio se liga às células sanguíneas e o gás carbônico é expirado, ou seja, se desprende das células.

B9 - Ao inspirar, as diferentes pressões (atmosférica e pulmonar) permitem que muito $\mathrm{O}_{2}$ entre nos pulmões. Assim, $\mathrm{O}$ ar inspirado tem mais $\mathrm{O}_{2}$ que $\mathrm{CO}_{2}$. $\mathrm{O} \mathrm{O}_{2}$ percorre nosso organismo e é utilizado em diversas atividades metabólicas. Essas atividades produzem $\mathrm{CO}_{2}$, que é levado até os bronquíolos para serem expirados. Na expiração há muito $\mathrm{CO}_{2}$ que foi produzido e um pouco do ar inspirado que não foi consumido.

C7 - Acredito que esta afirmação está correta, visto que pelo meu conhecimento seria prejudicial se inspirássemos mais gás carbônico do que oxigênio.

A afirmação da questão 4 foi redigida com o uso de dois termos imprecisos para se referir às concentrações de oxigênio e de gás carbônico no ar inspirado: rico em e pobre em. Na quinta questão, a afirmação compara, de forma propositalmente incorreta, 
a quantidade entre esses dois gases no ar inspirado e expirado. No ar, tanto inspirado quanto expirado, a concentração de oxigênio é maior que a de gás carbônico. $O$ mais adequado seria afirmar que a concentração de oxigênio no ar inspirado é maior do que no ar expirado, e a concentração de gás carbônico no ar inspirado é menor do que no ar expirado.

Em relação a esse tópico, observamos que as alunas compreendem que existe variação nas concentrações dos gases respiratórios, porém em um nível básico e em certos aspectos equivocam-se, como fez A7, ao afirmar que, "para fins didáticos, a nível de Ciências, Ensino Fundamental, creio que é válido citar a variação das concentrações de gás carbônico, devido à poluição do ambiente".

Também B9 manifestou-se de forma elementar, pois, para a aluna, "ao inspirar, as diferentes pressões (atmosférica e pulmonar) permitem que muito $\mathrm{O}_{2}$ entre nos pulmões. Assim, o ar inspirado tem mais $\mathrm{O}_{2}$ que $\mathrm{CO}_{2}{ }^{\prime \prime}$.

No primeiro caso, explicitamente a aluna relaciona as variações nas concentrações de gás carbônico a uma causa externa, como a poluição ambiental, e não como consequência de um processo interno de produção de $\mathrm{CO}_{2}$ a partir da respiração celular. A resposta deixa em dúvida se a aluna compreende que a respiração celular é a origem do $\mathrm{CO}_{2}$ expirado, ao afirmar "para fins didáticos, a nível de Ciências, Ensino Fundamental [...]". Nesse caso, estaria omitindo a respiração celular por considerar que é um conteúdo não trabalhado no Ensino Fundamental, o que consideramos pouco provável ao analisar as demais respostas dadas por $\mathrm{A} 7$, nas quais não se referiu à origem do $\mathrm{CO}_{2} \mathrm{a}$ partir do metabolismo celular.

No caso de B9, a aluna atribui a diferença na concentração de $\mathrm{O}_{2}$ entre ar inspirado e expirado a uma diferença de pressão entre ar atmosférico e pulmão e não à composição do ar atmosférico. É interessante observar que B9 demonstra conhecimento em um grau um pouco superior a de A7 e C7, ao citar, em suas respostas, expressões como cavidades nasais, bronquíolos, caixa torácica, difusão, diafragma, pressão atmosférica, músculos. As relações estabelecidas, entretanto, ainda são frágeis e, assim, a aluna não demonstra um conhecimento consistente acerca do fenômeno respiratório.

Em relação à $\mathrm{C7}$, a aluna considera a respiração um processo de obtenção de oxigênio, sem o qual o organismo morreria, sem, entretanto, explicitar o porquê. Em nenhuma das respostas é possível inferir que a aluna avança além dessa concepção, e na resposta à última questão fica evidente uma aprendizagem mecânica e irrefletida, quando A7 afirma: "Aprendi desta forma e nunca me atentei a esta afirmação, portanto creio que esteja correta." Essa observação corrobora resultados de estudo realizado por Sá, Souza e Jófili (2014, p. 17) com licenciandos de Biologia, no qual as autoras evidenciaram que os estudantes não parecem compreender bem o papel do gás oxigênio, alinhando suas explicações acerca das funções desse gás em âmbito de senso comum, "onde o elemento é visto como necessário à vida, se aproximando muitas vezes da ideia de combustivel necessário para o 'organismo funcionar'". 


\section{Momento 2 - Elaboração e leitura de esquemas}

O segundo momento da entrevista, composto pelas atividades de elaboração e de leitura com legendamento, é discutido na sequência.

\section{Elaboração de esquema}

Nesta primeira atividade do segundo momento da entrevista, solicitamos às participantes a elaboração de um esquema representando o trajeto dos gases respiratórios oxigênio e gás carbônico do exterior do corpo ao seu interior e novamente ao exterior. $\mathrm{A}$ partir desta atividade, orientamos as alunas a expressarem verbalmente o pensamento à medida que fossem fazendo o esquema.

Nenhuma informação adicional foi fornecida e o uso do material disponível foi de livre-escolha. Os esquemas elaborados por A7, B9 e C7 estão reproduzidos em escala reduzida na Figura 1 a seguir.

Figura 1 - Esquemas elaborados por A7, B9 e C7

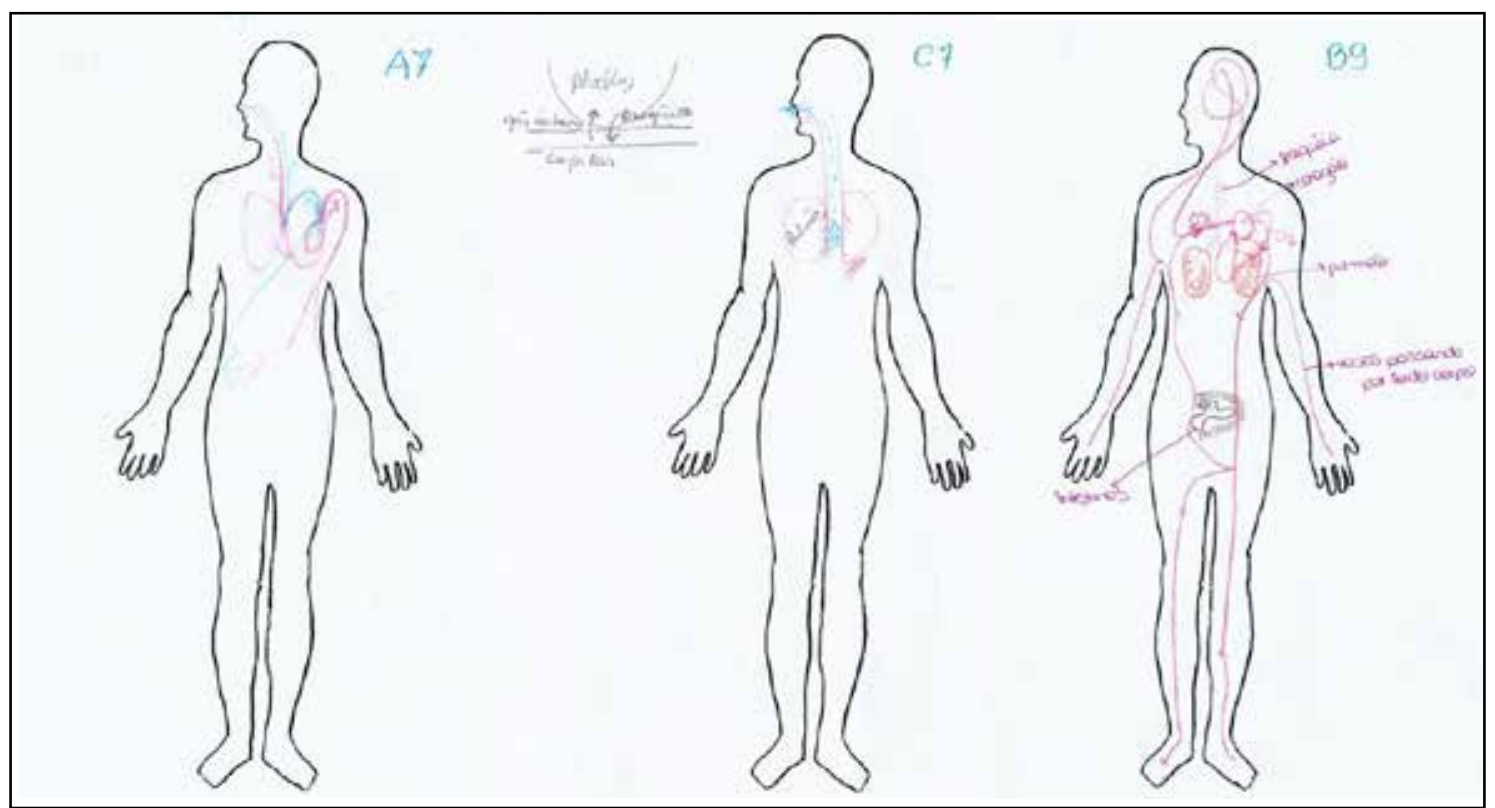

Observamos diferenças, em termos de estruturas representadas, entre os esquemas das três alunas. B9 representou e nomeou estruturas como traqueia, coração, pulmão, intestinos e vasos. Já os esquemas de $\mathrm{A} 7$ e C7 foram mais simples.

Embora C7 tenha representado fora do contorno o processo de troca gasosa entre alvéolo e capilar, a representação do trajeto dos gases no interior do corpo limitou-se ao traçado do ar entrando pela cavidade nasal e pela boca, indo até o pulmão e retornando ao exterior. A7 representou os gases entrando pelas cavidades nasais, passando pelos pulmões e pelo coração, e representou um trajeto na parte inferior do corpo até a região abdominal e de volta ao coração.

É importante ressaltar que o esquema de B9 não apenas representa mais estruturas, mas também amplia o traçado do trajeto dos gases respiratórios no interior do corpo, representando a passagem deles nos membros superiores, inferiores e na cabeça. 
Esta não é uma representação comum nos livros didáticos. De maneira geral, os esquemas do trajeto dos gases respiratórios representam a circulação sistêmica em relação à parte inferior do corpo, abaixo dos pulmões e coração, e acreditamos que este padrão de esquema pode ter influenciado a elaboração dos esquemas de A7 e C7.

É possível estabelecer a relação entre o conhecimento prévio das alunas e os esquemas elaborados. Comparando a transcrição da verbalização de A7 enquanto produzia o esquema com ele pronto, observamos que a dificuldade da aluna em expressar verbalmente o trajeto dos gases respiratórios, possivelmente em razão de um baixo nível de conhecimento acerca do assunto, refletiu-se na baixa qualidade do esquema elaborado, no sentido de representar uma ideia, processo ou estrutura.

De fato, se compararmos a verbalização transcrita a seguir com as respostas do questionário do primeiro momento da entrevista, o conhecimento de A7 sobre a respiração está ainda em um nível bastante superficial, interferindo na tarefa de esquematização. Observamos que a aluna apresenta lacunas de conhecimento e encontra dificuldade para articular a explicação, hesitando na denominação de determinados componentes, estruturas ou processos.

A7 - Pra representar... as diferenças das partículas né, de oxigênio e de gás carbônico. É... o gás carbônico ele... oxigênio, representado em vermelho. Ele vai, né, entrar nos pulmões, a princípio, o sangue que vai sair do coração, pobre em gás carbônico, vai pro cora... pros pulmões, vai liberar o gás carbônico e vai absorver o oxigênio e então vai voltar pro coração. Quando ele volta pro coração, ele vai se espalhar pelo corpo humano. Ele vai sair pelas artérias... pela artéria aorta né, e depois subsequentes arteríolas e capilares, se espalha pro corpo todo... tanto nas porções mais superficiais quanto nas porções internas, leva o oxigênio pras células e nas células o oxigênio ele éeee... ele é integrado né, sai da célula sanguínea e entra pra célula... pra célula vermelha. E, nessaaa... pra célula (risada pra dentro) pras células normais, né, lá ele vai ser utilizado em diversos processos metabólicos e ele... o, o... a molécula, a partícula, a hemácia né, que deixou essa partícula de oxigênio, ela vai começar a carrear uma partícula de $\mathrm{CO}_{2}$, que vai então consequentemente passar pelos capilares, entrar nas vênulas, passar pras veias, e então vai voltar pro coração. Quando volta pro coração é encaminhado aos pulmões... e então voltando ao passo de... sair (riso breve) e ser expirado.

Estudos como os de Pena e Quilez (2001) e de Gebre e Polman (2016), mostram que os alunos têm dificuldade em representar informações visualmente, e, ao fazê-lo, elaboram representações esquemáticas confusas e incompletas. Lowe (1987) chamou atenção para o fato de que a representação por meio de esquemas não é tarefa fácil, na medida em que implica a coordenação entre representar, relacionar e manipular entre si as estruturas que entram na composição do esquema.

Em relação às cores, $\mathrm{A} 7$ e $\mathrm{C} 7$ optaram pelo uso do vermelho e do azul com as seguintes justificativas:

A7 - É porque... é o que fica muito na cabeça da gente quando a gente vê em muitos livros, né, então sempre que a gente vê em livro didático, em livro de faculdade, qualquer coisa, eles sempre escolhem essas duas cores. Acho que relaciona muito porque o sangue a gente sempre vê vermelho e acha que eles querem representar um sangue intoxicado, entre aspas, é... como azul né, que seria mais oposto ao ver- 
melho, que seria o gás carbônico, e aí isso sempre fica na cabeça da gente, sempre que a gente pensa em... em pegar um sangue com oxigênio, um sangue com gás carbônico a gente pensa em azul e vermelho.

C7 - [...] quando eu penso em pulmão eu penso em vermelho. Não sei, eu acho... se eu desenhar tudo da mesma cor, é, o aluno pode pensar que é uma estrutura só. Por isso eu mudei assim pra diferenciar. Aí eu tô tentando desenhar; aqui seria a traqueia. Com o roxo. Aí eu voltei pro vermelho por que eu lembro que tem tipo uns capilares assim. (Longa pausa). Aí, agora eu peguei o azul claro pra representar $o$ ar entrando.

As cores, assim como as setas, os traços raiados, as fórmulas, as palavras, são elementos simbólicos usados na composição de esquemas. De maneira geral, nos esquemas que representam os sistemas do corpo humano o sangue arterial é representado em vermelho e o sangue venoso em azul. Pelas respostas de A7, infere-se que o uso dessas cores é pela familiaridade da aluna com elas por meio de representações em materiais escolares. Também nessas respostas fica mais uma vez clara a relação que A7 estabelece entre o gás carbônico e algo impuro, quando a aluna se refere ao "sangue intoxicado".

Quanto à verbalização de C7 - "quando eu penso em pulmão eu penso em vermelho" -, leva-nos a crer na possibilidade de que a imagem mental que a aluna tem de pulmão relaciona-se às imagens presentes nos livros didáticos, nos quais o pulmão é representado em tonalidades avermelhadas, semelhantes à cor do referente. Isso é um fator importante a ser considerado pelos autores de livros didáticos e pelos ilustradores de tais livros, levando em conta que eles se constituem em referência relevante para os alunos.

\section{Leitura de esquemas}

Nesta atividade, entregamos às entrevistadas três esquemas para leitura e legendamento. Foram omitidas as legendas originais que acompanhavam os esquemas para evitar interferências de informações externas à imagem em sua leitura.

O primeiro esquema para legendamento (Figura 2) consiste na representação dos caminhos percorridos pelos gases respiratórios, oxigênio e carbônico, do meio externo ao interior do corpo e vice-versa. Representava, sem escala e com cores-fantasia, a traqueia, os pulmões, as hemácias e algumas células do corpo de maneira inespecífica. 
Figura 2 - Esquema para legendamento

As legendas produzidas pelas participantes, a partir da leitura do esquema, são transcritas a seguir.

A7 - O ar inspirado, que é rico em oxigênio, é levado pela traqueia para os pulmões, onde entra em contato com as hemácias. Elas levam o $\mathrm{O}_{2}$ para as células do corpo e pegam o $\mathrm{CO}_{2}$ e levam para os pulmões, que expiram o $\mathrm{CO}_{2}$ e trocam por $\mathrm{O}_{2}$ novamente.

B9 - Representação simples de como ocorrem as trocas gasosas no organismo (esquema simplificado para facilitar a compreensão do sistema respiratório).

C7 - $\mathrm{O}$ ar inspirado rico em gás oxigênio entra no corpo por meio da traqueia e chega ao pulmão esquerdo, onde encon-

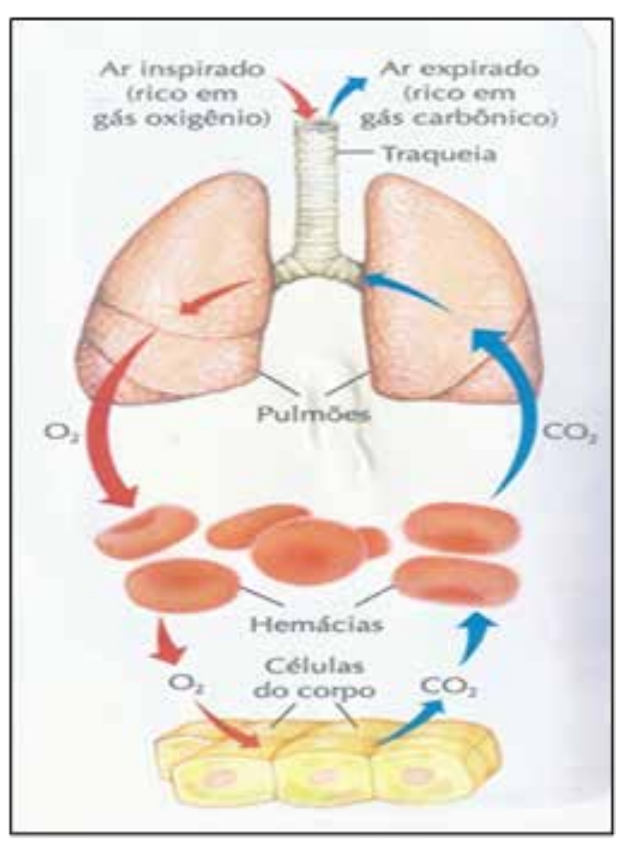
tra as hemácias que, por sua vez, irá levar este componente $-\mathrm{o}_{2}-$ para as células do corpo, onde haverá a troca pelo $\mathrm{CO}_{2}$ que será transportado para o pulmão, através das hemácias, e será liberado pela expiração.

Figura 3 - Esquema 2 para legendamento

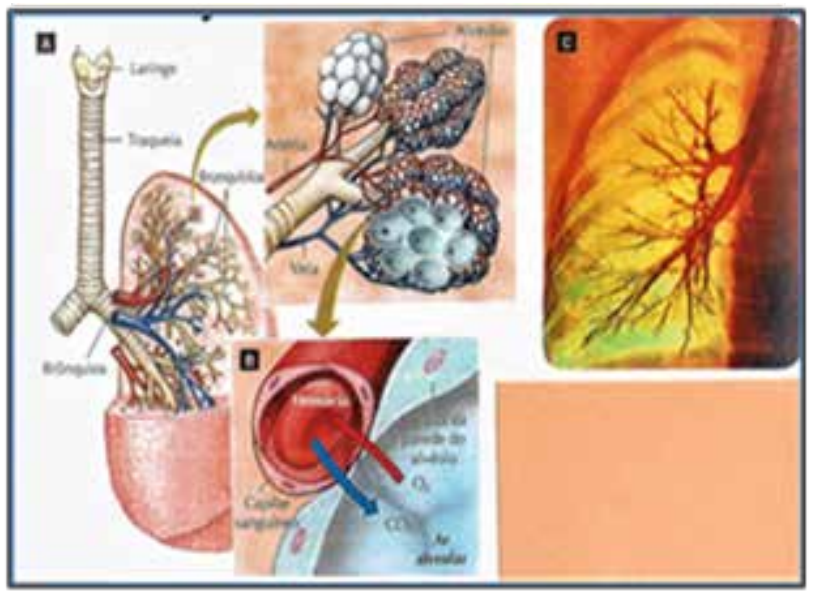

O segundo esquema é uma composição de imagens indicadas pelas letras A, B e C. Representava, em A e $B$, um corte do pulmão esquerdo, evidenciando as relações entre os alvéolos pulmonares e as extremidades dos bronquíolos. Apresentava ainda, em detalhe, a ampliação de um corte transversal de alvéolo e a representação da hematose. Em C, evidenciava as ramificações da artéria pulmonar por meio de uma arteriografia de pulmão humano. As legendas produzidas são como seguem.

A7 - (A) Demonstra as estruturas presentes no sistema respiratório e como interagem com o sistema circulatório.

A7- (B) Demonstra a troca gasosa que ocorre nos alvéolos, onde as hemácias deixam o $\mathrm{CO}_{2}$ e se ligam ao $\mathrm{O}_{2}$.

A7 - (C) Imagem real através de (raio X?) da artéria pulmonar.

B9 - (A) Apresentação de quase todos os órgãos do sistema respiratório. Nos bronquíolos há um zoom (seta) para enxergar melhor alvéolos, artérias e veias. 
B9 - (B) Há um segundo zoom onde se pode ver o local onde ocorre as trocas gasosas e os órgãos que são responsáveis.

B9 - (C) Representação real de um pulmão.

C7 - (A) Representação do caminho do ar inspirado (rico em gás oxigênio). Após passar pela traqueia o gás oxigênio chega até os bronquíolos onde serão transferidos até os alvéolos.

C7 - (B) Após o gás oxigênio chegar aos alvéolos, haverá a troca de gases. $O$ gás oxigênio presente nos alvéolos irá para o capilar e o gás carbônico transportado pela hemácia será transportado para os alvéolos.

C7 - (C)Representação de um "raio X" mostrando a estrutura dos brônquios, bronquíolos e alvéolos.

Figura 4 - Esquema 3 para legendamento

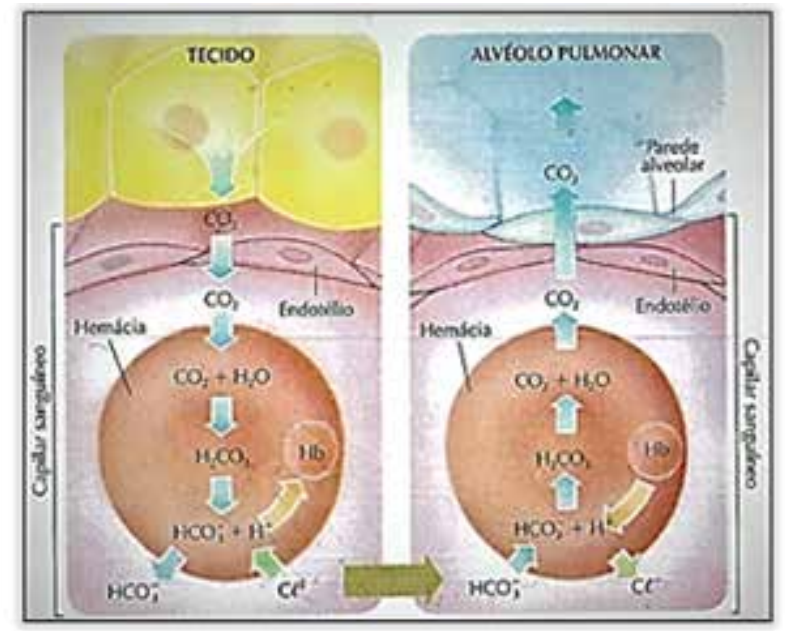

O terceiro e último esquema representa o transporte do gás carbônico $\left(\mathrm{CO}_{2}\right)$ e a dinâmica do balanço iônico nas hemácias. Para o esquema 3 foram elaboradas as seguintes legendas.

A7 - O tecido libera o $\mathrm{CO}_{2}$, as hemácias absorvem nos capilares e depois de percorrer todo caminho até os pulmões liberam o $\mathrm{CO}_{2}$ novamente.

B9 - Representação da saída de $\mathrm{CO}_{2}$ do tecido, sua captura pelas hemácias, localizadas no capilar sanguíneo e sua liberação para as artérias pulmonares, onde será expelido.

$\mathrm{C} 7$ - As células em amarelo liberam $\mathrm{CO}_{2}$ para as hemácias, no qual passará por umas reações químicas. Depois estas mesmas hemácias chegará para os alvéolos onde ocorrerá a transferência deste $\mathrm{CO}_{2}$.

Analisando os dados dos dois momentos das entrevistas, apresentamos as considerações a seguir.

Primeiramente, em relação ao esquema 1, que representa as trocas gasosas, é necessário mencionar que nele não está representado o coração, órgão que se relaciona de maneira bastante significativa com o sistema respiratório. Outro aspecto a ser considerado é que o esquema não faz referência explícita à respiração celular, como a origem do gás carbônico, assim como também não o fazem os esquemas 2 e 3.

Representar as trocas gasosas sem mencionar a origem do gás carbônico é uma omissão que pode trazer impactos na aprendizagem, na medida em que omite uma informação que possibilitaria ao aluno estabelecer relações entre processos que ocorrem em nível microscópico e macroscópico, cuja compreensão é necessária para a formação 
do conceito científico de respiração. Sá, Souza e Jófili (2014) apontam para a importância do diálogo entre processos que ocorrem nos diferentes níveis de organização dos seres vivos para a compreensão dos fenômenos.

Há ainda outro ponto a ser mencionado, que diz respeito às setas indicativas da entrada e da saída do ar. Da forma como está representado esse movimento, a leitura do esquema, como fez a aluna $\mathrm{C7}$, é de que o ar inspirado entra no organismo pelo pulmão direito e sai pelo pulmão esquerdo, o que é uma informação equivocada em relação ao fenômeno.

Sem dúvida, as imagens presentes nos livros didáticos podem reforçar ou até mesmo ser a origem de concepções por vezes em desacordo com o conhecimento científico vigente (ASCl; ÖZKAN; TEKKAYA, 2001; KWEN, 2005), e tendem a permanecer na estrutura cognitiva do aluno, influenciando a aprendizagem futura (VIENNOT, 1979; DRIVER, 1989).

Observamos também que $\mathrm{C7}$ fez uma leitura espelhada do esquema, pois o que a aluna leu como pulmão esquerdo é, de fato, a representação do pulmão direito. Há, sem dúvida, o desconhecimento de aspectos anatômicos, pois o esquema não deixa dúvidas quanto aos três lobos pulmonares de um lado e aos dois lobos pulmonares representados do outro lado, indicando tratar-se da representação do pulmão direito e esquerdo, respectivamente.

É nítida a leitura descritiva do esquema pelas alunas $A 7$ e C7, com a identificação dos elementos constituintes em primeiro nível, no que chamamos de leitura de superfície ou leitura de identificação. Não foi possível identificar no texto da legenda produzida, entretanto, algum sinal que apontasse para um avanço em direção a uma leitura em profundidade ou interpretativa.

É possível que B9 tenha alcançado o nível de leitura interpretativa no sentido expresso por Panofsky (1976, p. 54), ao manifestar-se em relação à iconologia como "um método de interpretação que advém da síntese mais que da análise". A aluna ultrapassa a leitura superficial, de mera descrição dos componentes do esquema, e sintetiza em um breve texto a interpretação do significado das estruturas e relações representadas com a seguinte redação:

Representação simples de como ocorrem as trocas gasosas no organismo (esquema simplificado para facilitar a compreensão do sistema respiratório).

Em relação ao esquema 2, observamos um pequeno avanço de $A 7$ em direção a uma leitura interpretativa e um pequeno retrocesso de B9, que realizou uma leitura mais descritiva, de identificação, sem estabelecer uma relação interpretativa entre os componentes do esquema. C7 continua em um nível de leitura de superfície.

Se compararmos os conhecimentos prévios das alunas, identificado por meio das respostas às atividades anteriores, com os legendamentos, nossas observações corroboram estudos como os de Kragten, Admiral e Rijlaarsdan (2013), Chittleborough e Treagust (2008) e Cook, Carter e Wiebe (2008), cujos resultados apontam uma estreita relação entre os conhecimentos prévios dos estudantes e o nível de leitura de esquemas apresentado pelos alunos. 
A transcrição da legenda de C7 confirma o que afirmamos, considerando que a aluna demonstrou ter pouco conhecimento acerca do processo respiratório, além de um nível bastante elementar de reconhecimento dos órgãos que compõem o sistema respiratório.

Em relação ao esquema 3, houve pouca diferença entre as alunas, que não avançaram para uma leitura interpretativa, limitando-se a descrever os constituintes do esquema e algumas relações superficiais. O que o esquema representa são as trocas gasosas em termos de regulação a partir da acidez do sangue. É possível que a dificuldade das alunas em avançar em direção a uma leitura interpretativa, resida na falta de conhecimentos relacionados a aspectos bioquímicos das trocas gasosas. A verbalização de $A 7$ durante o legendamento do esquema 3 suporta nossa afirmação:

Começa aqui, tecidooooo... Tá saindo $\mathrm{CO}_{2}$ do tecido e indo pra hemácia, dentro de um capilar sanguíneo, eles tão realizando as trocas aqui... Assim, principalmente por que a gente re...reconhece imediatamente de imagem, né. Depois que deu pra ver que tá escrito que é uma hemácia ali, mas se o $\mathrm{CO}_{2}$ tá saindo do tecido a gente... eu imagino né, pelo tema que a gente tá vendo, que é pra uma hemácia que ele tá se dirigindo. E... aqui ele tá sendo liberado para o alvéolo pulmonar... através né... de... das trocas novamente. Sinceramente, né, não... não presto muito atenção nas reações químicas aqui representadas né, nos passos químicos. Aí, eu acho que é o que menos desperta interesse (risos). Aquela coisa mais chata na cabeça (risos). Então, assim, não presto assim, se eu for, se tivesse estudando realmente isso, e fosse algo importante pra uma prova e pra uma avaliação, eu acho que eu estaria bastante focada nesses passos, se o professor dissesse que cobraria, eu provavelmente estaria escrevendo os [...].

Embora o esquema represente a saída do gás carbônico do tecido, a aluna não citou a respiração celular, o que evidenciaria, se o tivesse feito, a realização de uma inferência a partir da mobilização de conhecimentos prévios, assim como fez ao reconhecer a hemácia por meio da sua imagem. É importante observar a declaração de A7 em relação às informações do esquema envolvendo conteúdos de Química, os quais considera importantes no caso de serem cobrados em uma prova, porém não evidencia reconhecer a sua importância para o processo representado no esquema.

A dificuldade manifestada por $\mathrm{C} 7$ com conteúdos da Química, durante a leitura do terceiro esquema, possivelmente interferiu nessa leitura que se manteve em nível de superfície, com a mera descrição, o que reflete na forma como interpreta os esquemas:

C7 - Sim, foi a dificuldade exatamente aqui que eu, né? Eu não tenho tanto conhecimento de Química, assim, se eu pegasse isso daqui e me mostrasse eu teria muita dificuldade se não estivesse bem explicadinho.

Os resultados deste estudo corroboram trabalhos que apontam a dificuldade dos alunos em se expressar por meio de esquemas e em interpretar esquemas, em razão do fato de não possuírem uma ideia clara dos fenômenos (PENA; QUILEZ, 2001; GEBRE; POLMAN, 2016), embora as participantes desta investigação sejam professoras em formação, na fase final do curso de Graduação. Como apontam Bajd, Praprotnik e 
Matyašek (2010), a partir de estudo com professores primários em formação, os estudantes finalizam a educação básica e ingressam no Ensino Superior sem conhecimentos suficientes acerca do processo respiratório.

O domínio do vocabulário científico é outro fator que pode interferir na interpretação de esquemas. Observamos, na verbalização das alunas, que elas hesitavam nas respostas, usando palavras semelhantes foneticamente, como inspirar, expirar e respirar, indistintamente. Como reportaram Viennot e Kaminski (2006), entretanto, às vezes é difícil determinar se o aluno compreendeu um fenômeno, considerando que a resposta verbal imprecisa pode não corresponder à real compreensão.

Em relação às concepções, embora tenhamos realizado o estudo com alunas já no final da Graduação, identificamos concepções que se alinham àquelas apresentadas por estudantes no final da educação básica, o que reforça o seu caráter persistente. Concepções equivocadas acerca do fenômeno respiratório, considerado apenas um processo de troca de gases entre o organismo e o meio, por exemplo, bem como o reduzido ou inexistente domínio de conteúdos de outras áreas do conhecimento, como a Química, necessários para a compreensão do fenômeno, dificultaram a produção de sentidos a partir de uma leitura interpretativa dos esquemas.

Observamos que esquemas podem representar estruturas ou processos de forma equivocada ou incompleta, do ponto de vista do conhecimento científico vigente, reforçando concepções já existentes ou promovendo o surgimento de outras. Exemplificamos com o esquema 1, que apresenta uma seta vermelha indicando a entrada de oxigênio no lado direito e uma seta azul indicando que o gás carbônico sai pelo lado esquerdo. Esta forma de representar a troca de gases pode levar a dois equívocos: apenas oxigênio entra no pulmão, e dele sai apenas gás carbônico; e o ar entra apenas pelo lado direito do sistema respiratório e sai apenas pelo lado esquerdo.

Ficou claro, a partir dos resultados, que é possível que as alunas desconheçam a origem do gás carbônico expirado, não estabeleçam relação desse gás com a respiração celular ou, ainda, não relacionem respiração celular e respiração pulmonar, posto que os esquemas elaborados omitiram esse processo. Acreditamos que o fato de os conteúdos serem trabalhados de forma compartimentalizada durante a educação básica, pode ser uma das causas dessa omissão.

Os resultados evidenciaram que as alunas, na maior parte das atividades de leitura de esquemas, tiveram dificuldade em avançar além de um nível descritivo, de reconhecimento de estruturas representadas, mantendo-se no que chamamos de leitura superficial ou de identificação.

Finalizando, é importante considerar a idiossincrasia na leitura de um esquema no contexto de sala de aula. Uma vez que nem todos os alunos irão alcançar o nível de leitura interpretativa, é necessário individualizar e avaliar cuidadosamente os benefícios dessas imagens nos processos de aprendizagem.

\section{CONSIDERAÇÕES FINAIS}

Ainda que um dos objetivos do ensino de Ciências e Biologia, expresso em documentos oficiais, seja o desenvolvimento da competência para o uso de imagens, práticas docentes concretas e sistematizadas, que apontem para a consecução desse objeti- 
vo, ainda são pontuais. É necessário que a discussão sobre a utilização dessas imagens esteja presente nas salas de aula de cursos de formação de docentes e que os professores da Educação Básica tenham por hábito discutir essas imagens com seus alunos.

Do ponto de vista estrutural, esquemas são representações visuais complexas, elaboradas a partir da combinação de elementos que representam seu referente por analogia, por convenção ou por ambos, cujo arranjo espacial pode interferir na representação de uma estrutura, de uma relação ou de um processo. Por conta dessas peculiaridades, produzir sentido a partir da leitura de esquemas requer do leitor não apenas a identificação desses elementos, mas também o estabelecimento das relações entre eles.

Ocorre que, para a identificação e o correto estabelecimento das relações evidenciadas no esquema, o aluno precisa dominar os códigos de representação usados em sua elaboração, o que já Ihe possibilita uma leitura de superfície, e mobilizar conhecimentos prévios para atribuir significados aos componentes identificados, realizando, assim, uma leitura interpretativa.

Assim como a leitura de um texto escrito, a leitura de um texto imagético também deve ser ensinada e aprendida. Ressaltamos que o aprendizado da leitura das representações visuais na forma de imagens não se limita apenas ao aluno da educação básica, devendo contemplar também o aluno da educação superior, em especial nos cursos de formação de professores. Afinal, o professor precisa saber usar imagens para ensinar seu aluno a fazer uso desse recurso, particularmente as imagens do tipo esquema.

Dessa forma, a investigação realizada, ainda que não possibilite generalizações, aponta para a necessidade de ampliar as pesquisas em ensino de Ciências e Biologia focadas na leitura de imagens do tipo esquema, notadamente em relação à aprendizagem de conceitos científicos.

Cabe considerar, também, a realização de pesquisas com o mesmo propósito no âmbito de formação de professores de Ciências e Biologia, uma vez que os resultados poderão ser utilizados no planejamento de disciplinas específicas dos cursos de Graduação, visando a subsidiar as discussões acerca da utilização de esquemas no ensino e aprendizagem de conceitos científicos.

\section{REFERÊNCIAS}

ACEDO, P. H.; FIEDLER-FERRARA JÚNIOR, N. Concepções de alunos de Ensino Médio sobre a respiração humana. In: ENCONTRO DE PESQUISA EM ENSINO DE FÍSICA, 11., 2008, Curitiba, Atas eletrônicas [...]. Disponível em: http://www.sbf1.sbfisica.org.br/eventos/epef/xi/atas/resumos/T0056-1.pdf. Acesso em: 30 jul. 2017.

AMABIS, J. M.; MARTHO, G. R. Biologia 2: biologia dos organismos. 3. ed. São Paulo: Moderna, 2009.

ASCI, Z.; ÖZKAN, S.; TEKKAYA, C. Students' misconceptions about respiration: a cross-age study. Education and Science, v. 26, n. 120, p. 29-36, 2001.

BANET, E.; NÚÑEZ, F. Esquemas conceptuales de los alumnos sobre la respiración. Enseñanza de las Ciencias, v. 8, n. 2, p. 105-110, 1996.

BAJD, B.; PRAPROTNIK, L.; MATYÁŠEK, J. Students' ideas about respiration: a comparison of slovene and czech students. School and Health, v. 21, p. 245-251, 2010.

BARLEX, D.; CARRÉ, C. Visual communication in science. Cambridge: University Press, 1985.

BOWEN, G. M.; ROTH, W. M. Why students may not learn to interpret scientific inscriptions. Research in Science Education, v. 32, p. 303-327, 2002. 
BUCKLEY, B. C. Interactive multimedia and model-based learning in biology. International Journal of Science Education, v. 22, p. 895-935, 2000.

CALADO, I. A utilização educativa das imagens. Porto: Porto Editora, 1994.

CHENG, P. C. H. Unlocking conceptual learning in mathematics and science with effective representational systems. Computers and Education, v. 33, p. 109-130, 1999.

CHITTLEBOROUGH, G.; TREAGUST, D. Correct interpretation of chemical diagrams requires transforming from one level of representation to another. Research in Science Education, v. 38, p. 463-482, 2008.

COOK, M.; CARTER, G.; WIEBE, E. N. The interpretation of cellular transport graphics by students with low and high prior knowledge. International Journal of Science Education, v. 30 n. 2, p. 239-261, fev. 2008

DRIVER, R. Student's conceptions and the learning of Science. International Journal of Science Education, v. 11, special issue, p. 481-490, 1989.

GEBRE, E. H.; POLMAN, J. L. Developing young adults' representational competence through infographic-based science news reporting. International Journal of Science Education, v. 38, n. 18, p. 2.667-2.687, 2016.

GOLDSMITH, E. Research into Illustration - an Aproach and Review. Cambridge: Cambridge University Press, 1984.

KRAGTEN, M.; ADMIRAAL, W.; RIJLAARSDAM, G. Diagrammatic Literacy in Secondary Science Education. Research in Science Education, v. 43, p. 1.785-1.800, 2013.

KOCH, I. V.; ELIAS, V. M. Ler e compreender: os sentidos do texto. 2. ed. São Paulo: Contexto, 2008.

KWEN, B. H. Teachers' misconceptions of biological science concepts as revealed in science examination papers. In: INTERNATIONAL EDUCATION RESEARCH CONFERENCE, 2005, Sydney. Anais [...]. Meulbourne: AARE, 2005. Disponível em: https://www.aare.edu.au/data/publications/ 2005/boo05099.pdf. Acesso em: 15 set. 2016.

KOTZEBUE, L.; GERSTL, M.; NERDEL, C. Common mistakes in the construction of diagrams in biological contexts. Research in Science Education, v. 45, p. 193-213, 2015.

LIU, Y.; WON, M.; TREAGUST, D. Secondary biology teachers' use of different types of diagrams for different purposes. In: EILAM, B.; GILBERT, J. K. (ed.). Models and modeling in science education, 8, 2014 [ResearchGate version]. DOI: 10.1007/978-3-319-06526-7_5

LOWE, R. Drawing out ideas: a neglected role for scientific diagrams. Research in Science Education, v. 17, p. 56-66, 1987.

LUís, N. M. L. Concepções dos alunos sobre respiração e sistema respiratório: um estudo sobre a sua evolução em alunos do ensino básico. 2004, 167 f. Dissertação (Mestrado em Educação) - Instituto de Educação e Psicologia, Universidade do Minho, Portugal, 2004.

MARTINS, I. O papel das representações visuais no ensino-aprendizagem de ciências. In: ENCONTRO NACIONAL DE PESQUISA EM ENSINO DE CIÊNCIAS, 1., 1997, Águas de Lindoia. Anais [...]. Águas de Lindoia, 1997. p. 294-299.

MARTINS, M. C.; PICOSQUE, G.; GUERRA, M. T. Didática do ensino da arte: a língua do mundo. São Paulo: FTD. 1998.

MANINI, M. P. A leitura de imagens fotográficas: preliminares da análise documentária de fotografias. ENCONTRO NACIONAL DE PESQUISA EM CIÊNCIA DA INFORMAÇÃO, 12., 2011, Brasília. Atas eletrônicas [...]. Brasília: UnB, 2011. Disponível em: http://enancib.ibict.br/index.php/enancib/enancibXII/paper/ view/783. Acesso em: 23 maio 2017.

PANOFSKY, E. Significado nas artes visuais. São Paulo: Perspectiva, 1976.

PENA, B. M.; QUILEZ, M. J. G. The importance of images in astronomy education. International Journal of Science Education, v. 23, n. 11, p. 1.125-1.135, 2001.

ROTH, W. M.; POZZER-ARDENGHI, L.; HAN, J. Y. Critical graphicacy: understanding visual representation practices in school science. Netherlands: Springer, 2005.

SÁ, R. G. B.; SOUZA, A. F.; JÓFILI, Z. M. S. A compreensão do processo respiratório por licenciandos em biologia: implicações para sua formação. In: COLÓQUIO INTERNACIONAL DE PESQUISA EM EDUCAÇÃO SUPERIOR: formação de professores e ensino por competências, 2., 2014, João Pessoa. Disponível em: https://www.researchgate.net/publication/269394863. Acesso em: 26 set. 2016.

SÁ, R. G. B. et al. Sequência didática interativa no estudo do conceito de respiração. ENCONTRO NACIONAL DE PESQUISA EM EDUCAÇÃO EM CIÊNCIAS, 10., 2015, Águas de Lindoia. Atas eletrônicas [...]. Águas de Lindoia: Abrapec, 2015. Disponível em: http://www.abrapecnet.org.br/enpec/x-enpec/anais2015/listaresumos.htm. Acesso em: 24 set. 2016. 
SÁ, R. G. B.; JÓFILI, Z. M. S.; CARNEIRO-LEÃO, A. M. Um estudo sobre a evolução do conceito de respiração. In: ENCONTRO NACIONAL DE PESQUISA EM ENSINO DE CIÊNCIAS, 8., 2011, Campinas. Atas eletrônicas [...]. Rio de Janeiro: UFRJ, 2011. Disponível em: http://abrapecnet. org.br/ atas_enpec/viiienpec/ resumos/R1457-2.pdf. Acesso em: 25 set. 2016.

SÁ, R. G. B.; JÓFILI, Z. M. S.; CARNEIRO-LEÃO, A. M. Concepç̃̃es espontâneas de respiração pulmonar por alunos do Ensino Fundamental 1. In: ENCONTRO NACIONAL DE PESQUISA EM ENSINO DE CIÊNCIAS, 5., 2005, Bauru. Atas eletrônicas [...]. Bauru: Abrapec, 2006. Disponível em: http://abrapecnet.org.br/atas_ enpec/venpec/conteudo/artigos/1/pdf/p609.pdf. Acesso em: 25 set. 2016.

SÁ, R. G. B; JÓFILI, Z. M. S.; CARNEIRO-LEÃO, A. M. Refletindo a construção do conceito sistêmico de respiração entre alunos de pós-graduação stricto sensu. In: ENCONTRO NACIONAL DE PESQUISA EM ENSINO DE CIÊNCIAS, 7., 2009, Florianópolis. Atas eletrônicas... Belo Horizonte: UFMG, 2009. Disponível em: http://posgrad. fae.ufmg.br/posgrad/viienpec/pdfs/1662.pdf. Acesso em: 25 set. 2016.

VIENNOT; L. Spontaneous reasoning in elementary dynamics. European Journal of Science Education, v. 1, n. 2, p. 205-221, 1979.

VIENNOT; L.; KAMINSKI, W. Can we evaluate the impact of a critical detail? The role of a type of diagram in understanding optical imaging. International Journal of Science Education, v. 28, n. 15, p. 1.867-1.885, 15 dez. 2006.

WALTY, I. L.; FONSECA, M. N. S.; CURY, M. Z. F. Palavra e imagem: leituras cruzadas. Belo Horizonte: Autêntica, 2000. 